Original article

\title{
Prevalence and risk factors for heterotopic gastric mucosa of the upper esophagus among men undergoing routine screening colonoscopy
}

\author{
S. M. Govani, ${ }^{1}$ V. Metko, ${ }^{1}$ J. H. Rubenstein ${ }^{1,2}$ \\ ${ }^{1}$ Division of Gastroenterology, Department of Internal Medicine, University of Michigan Medical School, and \\ ${ }^{2}$ Center for Clinical Management Research, Veterans Affairs Medical Center, Ann Arbor, Michigan, USA
}

SUMMARY. The prevalence of heterotopic gastric mucosa of the upper esophagus (inlet patch) has a wide range depending on the method and detail of examination. The inlet patch is believed to be a congenital malformation that rarely leads to symptoms. We aimed to quantify the prevalence of the inlet patch in a non-referred population and determine if there are any risk factors or associated symptoms. Men between ages $\mathbf{5 0}$ and $\mathbf{7 9}$ presenting for routine colonoscopy at two clinical sites were recruited to undergo an upper endoscopy. Endoscopists were prompted to examine for the presence of the inlet patch. Of the 822 enrolled patients, 795 had data regarding the presence of an inlet patch. Of these, $55(6.9 \%)$ had an inlet patch identified. Education was inversely associated (odds ratio $[\mathrm{OR}]$ advanced degree vs. high school or less $=0.310 ; 95 \%$ confidence interval $[\mathrm{CI}]=0.111,0.869)$, and tobacco use was positively associated with the presence of an inlet patch (current vs. never smokers $\mathrm{OR}=2.87 ; 95 \% \mathrm{CI}=1.23$, 6.69; former vs. never smokers $\mathrm{OR}=1.93 ; 95 \% \mathrm{CI}=0.922,4.02$ ). No association between the inlet patch and symptoms of heartburn, globus, or dysphagia was found. In a cross-sectional study of colon cancer screenees, inlet patches were common and were not associated with symptoms. Tobacco use appears to be associated with the presence of an inlet patch.

KEY WORDS: heterotopic gastric mucosa, inlet patch, tobacco.

\section{INTRODUCTION}

An inlet patch is defined as gastric heterotopic mucosa in the upper esophagus; the condition was first described more than a century ago. ${ }^{1}$ In prior studies, the prevalence ranges broadly from $0.3 \%$ to $10 \%$ of endoscopies, likely due to how carefully the upper esophagus is examined. ${ }^{2-4}$ While a majority of patients are asymptomatic, symptoms of globus and dysphagia have been associated with these endoscopic findings, ${ }^{5}$ and complications associated with the inlet patch in the literature include stricture, fistulas, adenocarcinoma, and perforation. ${ }^{6-8}$

Address correspondence to: Dr Joel H. Rubenstein, MD, MSc, Veterans Affairs Medical Center 111-D, 2215 Fuller Road, Ann Arbor, MI 48105, USA. Email: jhr@umich.edu

Specific author contributions: SMG performed the data analysis, and drafted and revised the manuscript; VM collected and cleaned the data; JHR initiated the project, reviewed the data analysis, revised the manuscript, and supervised the project. All authors reviewed the final manuscript before submission. Conflicts of interest: The authors have no conflicts of interest to declare.

Financial support: Research and salary funding was provided by the National Institutes of Health (JHR: K23DK079291).
The finding itself is believed to be congenital, but associations with alcohol use and Barrett's esophagus have been found. ${ }^{9}$ To our knowledge, no association with tobacco has been reported in the literature.

We recently completed a large prospective study designed to assess risk factors for Barrett's esophagus. In that study, 822 men between the ages of 50 and 79 undergoing routine colonoscopy for colorectal cancer screening also underwent an upper endoscopy regardless of symptoms and a battery of surveys. As part of that study, endoscopists were directed by a research coordinator specifically to examine for the presence of an inlet patch. This study provided a unique opportunity to quantify the prevalence of the inlet patch and determine if there are any risk factors to suggest that it is an acquired condition, and to determine whether inlet patches are associated with symptoms.

\section{METHODS}

Men between the ages of 50 and 79 were enrolled in the Newly Diagnosed Barrett's Esophagus Study

(C) 2014 International Society for Diseases of the Esophagus 
from February 2008 to December 2011. These patients were presenting for screening or surveillance colonoscopy at the Ann Arbor Veteran's Affairs Medical Center or the University of Michigan's East Ann Arbor Medical Procedures Center. The study design is described in detail elsewhere. ${ }^{10,11}$ Briefly, patients were excluded if their age was not within 50-79 years, if they were female, if they had undergone prior upper endoscopy, or had a prior history of Barrett's esophagus or esophagectomy. If the colonoscopy was being done for bleeding (including occult blood), iron deficiency anemia, diarrhea, and inflammatory bowel disease-related surveillance, patients were also excluded. Those with a history of ascites, esophageal varices, history of cancer in the last 5 years (except non-melanomatous skin cancers), or those who were inpatients were excluded.

Prior to endoscopy, patient's height, weight, and hip circumference were measured in duplicate. Patients were then questioned regarding alcohol, tobacco, and medication use in addition to gastrointestinal symptoms. A novel questionnaire regarding gastroesophageal reflux disease (GERD) symptoms was administered. Alternative instruments available at the time of initiation of the study, such as the Mayo Gastroesophageal Reflux Questionnaire, did not discriminate between past history of reflux symptoms and the use of histamine receptor blockers and proton pump inhibitors (PPI). Portions of this questionnaire can be found in the supplementary material for the original paper. ${ }^{10}$ For the purposes of this analysis, we utilized responses to queries regarding time since onset of heartburn symptoms, and typical frequency of either heartburn or regurgitation while not taking acid-reducing medications. Questions regarding globus sensation, defined as the sensation of something lodged in the patient's throat when not eating or drinking, and dysphagia were also included in the questionnaire. Detailed questions regarding dysphagia to type (solids, liquids, or pills), location, and frequency were asked; for the purpose of our analysis, we characterized dysphagia only as the dichotomous answer to a query regarding problems with swallowing. The questions regarding heartburn, regurgitation, globus, and dysphagia were administered by a research assistant prior to the endoscopy procedure. The remaining questions, including regarding tobacco use, were typically completed by the subjects after the procedure at home and returned by postal mail.

The research assistant queried the endoscopist in each case regarding findings and measurements. The endoscopist was asked specifically to examine for the presence of an inlet patch using both white light and narrow band imaging. If one was found, the location, size (circumferential aspect), and distance to proximal and distal aspects of the patch were recorded. Biopsies were not routinely obtained of an inlet patch. If Barrett's esophagus was suspected endoscopically, biopsies were obtained and reviewed by a pathologist with expertise in Barrett's esophagus. Patients with columnar mucosa in the distal esophagus identified endoscopically and confirmed to harbor specialized intestinal metaplasia on histology were classified to have Barrett's esophagus. There were trainees involved in some procedures, but this information was not recorded so the percentage of procedures and how this affected the findings of an inlet patch are unknown. An attending physician was always present for these endoscopies.

\section{Analysis}

Data were recorded in Microsoft Access and then imported to SAS 9.3 for analysis (Sas Inc., Cary, NC, USA). Chi-square or Fisher's exact tests were used where statistically appropriate to compare categorical variables, and the student's $t$-test was used to analyze continuous variables. Linear trends where analyzed by the Mantel-Haenszel chi-square test after ensuring that all cells had expected values greater than 5. Logistic regression models were fitted adjusting for potential confounders.

\section{RESULTS}

Of the 822 patients enrolled, 463 were from the university site and 359 were from the Veteran's Affairs Medical Center. Of these 822, 27 patients had missing data on the presence of the inlet patch $(3.3 \%)$. Of these 27 patients, three cases specifically noted difficulty in assessing for the presence of a patch due to patient intolerance. Of the remaining 795, 55 had an inlet patch on endoscopy (6.9\%). While most patients had only one patch $(85.5 \%)$, one patient did have four distinct patches (Fig. 1). The majority of patients had a patch that encompassed less than $25 \%$ of the circumference and most were less than $2 \mathrm{~cm}$ in length (Fig. 1). Inlet patch was most likely to be found on the patient's left than any other location $(P=0.03)$. Further details about the number of patches per patient, location, length, circumference, and distance from the upper esophageal sphincter are found in Figure 1.

Demographics were similar for those with and without inlet patch, with the exception of education which was inversely associated with inlet patch (33\% had high school education or less vs. $20 \%$, Table 1). There was no difference in age, race, household income, body mass index, or waist-hip ratio between the two groups. Of the 822 patients, $16(2 \%)$ did not complete any portion of our GERD questionnaire.

There were no statistically significant differences between those with and without inlet patches with regard to symptoms, including heartburn, globus, or dysphagia (Table 1). Examining only those with 
a

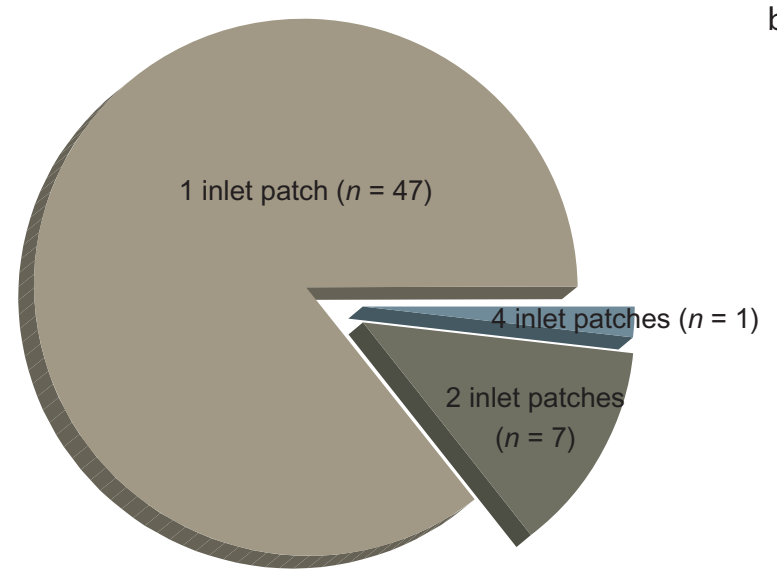

c

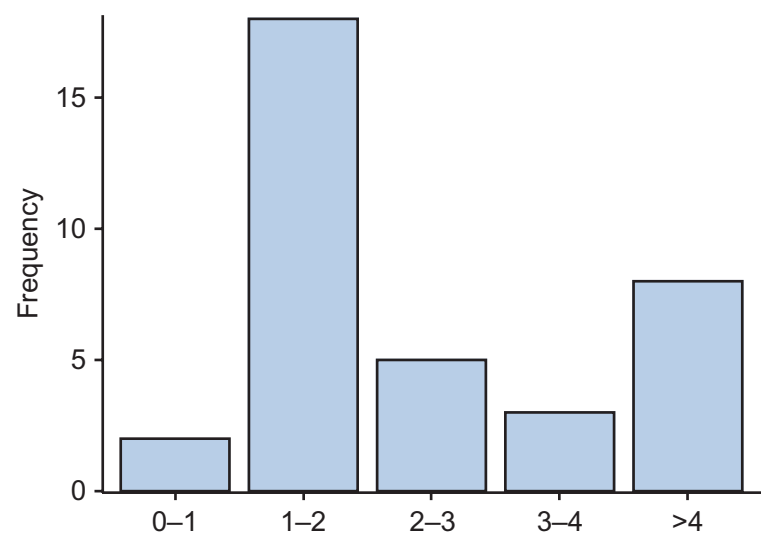

Distance from upper esophageal sphincter to top of inlet patch $(\mathrm{cm})$ b

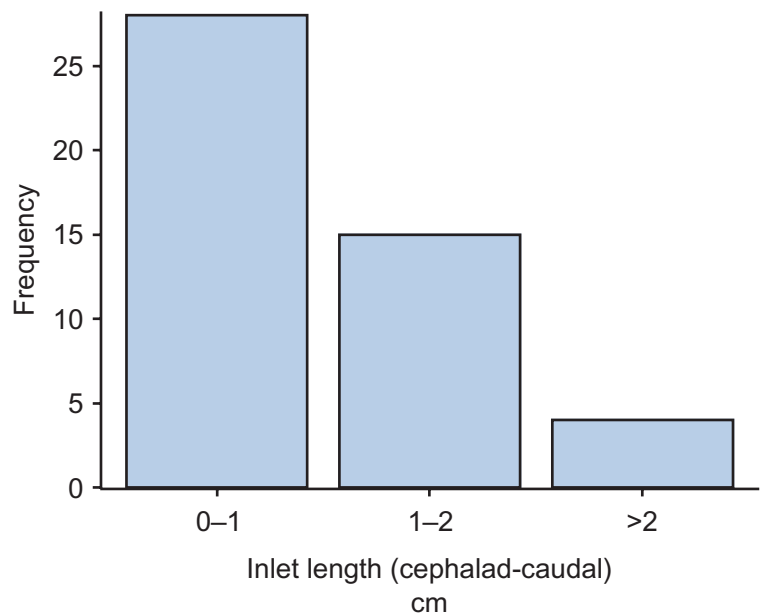

d

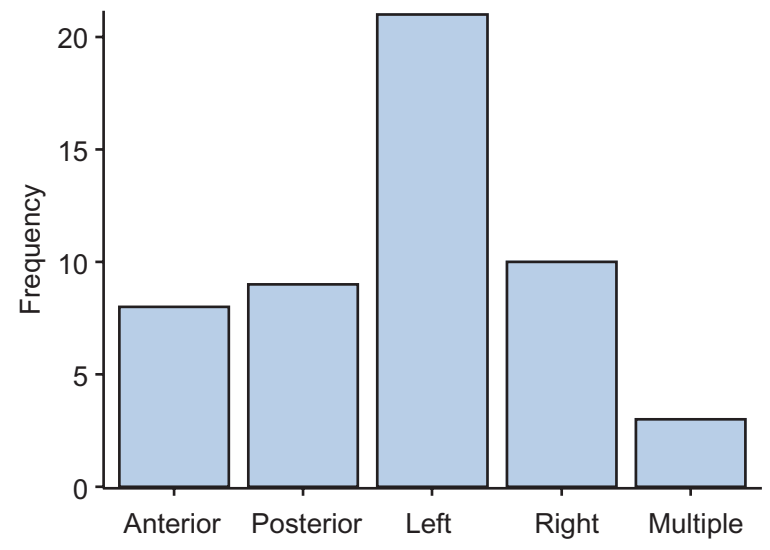

Location of inlet patch with respect to patient

e

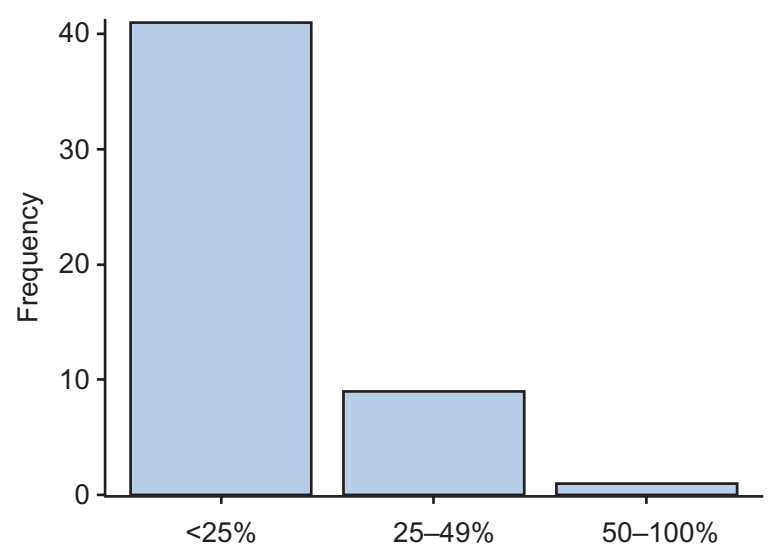

Percent of esophageal circumference involved

Fig. 1 Characteristics of the inlet patch findings. A pie chart of the number of inlet patches found per patient is located in panel (a). Panel (b) a histogram (absolute counts) of the inlet patch length from proximal to distal edge in centimeters. Panel (c) shows the distance from the upper esophageal sphincter to the proximal edge of the patch in centimeters. Panel (d) shows the distribution of the patch location, with respect to the patient. Finally, panel (e) shows the percentage circumference that the patch encompasses in this population. 
Table 1 Comparison of characteristics between patients with an inlet patch and those without a patch

\begin{tabular}{|c|c|c|c|}
\hline & Inlet patch $(n=55)$ & No inlet patch $(n=740)$ & $P$-value \\
\hline Age (SD) & $58.5(6.5)$ & $58.8(6.8)$ & 0.72 \\
\hline Race $(\%)$ & & & 0.61 \\
\hline Caucasian & $43(93.5)$ & $635(89.8)$ & \\
\hline Not Caucasian & $3(6.5)$ & $72(10.2)$ & \\
\hline Education & & & 0.05 \\
\hline High school or less & $16(33.3)$ & $145(20.4)$ & \\
\hline Some college up to bachelor's degree & $27(56.3)$ & $421(59.1)$ & \\
\hline Advanced degree & $5(10.4)$ & $146(20.5)$ & \\
\hline Annual income (\$) & & & 0.64 \\
\hline$<40000$ & $21(44.7)$ & $259(38.8)$ & \\
\hline $40000-100000$ & $15(31.9)$ & $215(32.2)$ & \\
\hline$>100000$ & $11(23.4)$ & $194(29.0)$ & \\
\hline Site $(\%)$ & & & 0.39 \\
\hline MPC & $28(50.9)$ & $421(56.9)$ & \\
\hline VA & $27(49.1)$ & $319(43.1)$ & \\
\hline BMI $(\%)$ & & & 0.32 \\
\hline BMI $<20$ & $1(1.9)$ & $7(1.0)$ & \\
\hline BMI 20-25 & $11(20.4)$ & $123(16.8)$ & \\
\hline BMI $25-30$ & $24(44.4)$ & $266(36.2)$ & \\
\hline $\mathrm{BMI}>30$ & $18(33.3)$ & $338(46.1)$ & \\
\hline Waist to hip ratio by tertiles & & & 0.73 \\
\hline First $(<0.979)$ & $21(38.2)$ & $246(33.3)$ & \\
\hline Second $(0.980-1.024)$ & $16(29.1)$ & $245(33.1)$ & \\
\hline Third $(>1.024)$ & $18(32.8)$ & 248 (33.6) & \\
\hline Biopsy proven Barrett’s (\%) & & & 0.8 \\
\hline Yes & $5(9.1)$ & $63(8.5)$ & \\
\hline No & $50(90.9)$ & $676(91.5)$ & \\
\hline Hiatal hernia $>2 \mathrm{~cm}$ & & & 0.88 \\
\hline Yes & $6(11.1)$ & $87(11.8)$ & \\
\hline No & 48 (88.9) & $651(88.2)$ & \\
\hline GERD frequency off meds & & & 0.32 \\
\hline$>1$ weekly & $13(24.1)$ & 135 (18.6) & \\
\hline Not weekly & $41(75.9)$ & $590(81.4)$ & \\
\hline Heartburn for 3 continuous months & & & 0.7 \\
\hline Never & $45(83.3)$ & $573(79.3)$ & \\
\hline In the last year only & 0 & $24(3.3)$ & \\
\hline Started $1-3$ years ago & $2(3.7)$ & $27(3.7)$ & \\
\hline Started $>3$ years ago & $7(13.0)$ & $99(13.7)$ & \\
\hline Globus & & & 0.75 \\
\hline Yes & $5(9.3)$ & $77(10.6)$ & \\
\hline No & $49(90.7)$ & $648(89.4)$ & \\
\hline Dysphagia & & & 0.49 \\
\hline Yes & $4(7.4)$ & $75(10.3)$ & \\
\hline No & $40(92.6)$ & $650(89.7)$ & \\
\hline ASA use & & & 0.61 \\
\hline None & $34(61.8)$ & $412(55.7)$ & \\
\hline For $<5$ years & $8(14.6)$ & $143(19.3)$ & \\
\hline For $\geq 5$ years & $13(23.6)$ & $185(25.0)$ & \\
\hline NSAID use & & & 0.81 \\
\hline None & $43(78.2)$ & $552(74.6)$ & \\
\hline For $<5$ years & $8(14.6)$ & $118(16.0)$ & \\
\hline For $\geq 5$ years & $4(7.3)$ & $70(9.0)$ & \\
\hline PPI use $(\%)$ & & & 0.8 \\
\hline None & $50(90.9)$ & $646(87.3)$ & \\
\hline $\mathrm{PPI}<5$ years & $3(5.5)$ & $64(8.7)$ & \\
\hline PPI $>5$ years & $2(3.6)$ & $30(4.0)$ & \\
\hline H2RA use $(\%)$ & & & 0.77 \\
\hline None & $50(94.6)$ & 693 (93.7) & \\
\hline $\mathrm{H} 2 \mathrm{RA}<5$ years & $2(3.6)$ & $38(5.1)$ & \\
\hline $\mathrm{H} 2 \mathrm{RA}>5$ years & $1(1.8)$ & $9(1.2)$ & \\
\hline
\end{tabular}

ASA, aspirin; BMI, body mass index; GERD, gastroesophageal reflux disease; MPC, Medical Procedures Center; NSAID, non-steroidal anti inflammatory drugs; PPI, proton pump inhibitor; VA, Veteran's Affairs Medical Center.

larger inlet patches $(>1 \mathrm{~cm}$ in length or $>25 \%$ of the esophageal circumference) also did not reveal an association with these symptoms. There was also no difference in PPI use, type 2 histamine receptor blocker use, aspirin use, or other non-steroidal anti (C) 2014 International Society for Diseases of the Esophagus inflammatory drug use. Neither group was more likely to have a hiatal hernia $(>2 \mathrm{~cm})$ or biopsyproven Barrett's esophagus (Table 1).

Patients with inlet patches had a heavier smoking history (mean 23.7 pack-years vs. 16.3 pack-years, 
Table 2 The effects of tobacco and alcohol use on the presence of inlet patch

\begin{tabular}{|c|c|c|c|c|}
\hline & Inlet patch $(n=55)$ & No inlet patch $(n=740)$ & OR $(95 \% \mathrm{CI})$ & $P$-value \\
\hline Pack-years of cigarettes & & & & 0.02 \\
\hline 0 pack-years & $12(25.0)$ & $241(34.2)$ & 1 & \\
\hline 1-34 pack-years & $12(25.0)$ & $246(34.9)$ & $1.42(0.623-3.21)$ & \\
\hline$>35$ pack-years & $24(50.0)$ & $218(30.9)$ & $2.69(1.31-5.52)$ & \\
\hline Linear trend & & & & 0.01 \\
\hline \multicolumn{5}{|l|}{ Smoking status } \\
\hline Never & $11(23.9)$ & $281(40.6)$ & 1 & 0.04 \\
\hline Former & $23(50.0)$ & $305(44.0)$ & $1.93(0.922-4.02)$ & \\
\hline Current & $12(26.1)$ & $107(15.4)$ & $2.87(1.23-6.69)$ & \\
\hline Linear trend & & & & 0.01 \\
\hline Smoker by duration since use & & & & 0.06 \\
\hline Never & $11(24.4)$ & $281(40.3)$ & 1 & \\
\hline Quit $>10$ years ago & $15(33.3)$ & $243(34.8)$ & $1.58(0.711-3.50)$ & \\
\hline Quit $<10$ years ago & $7(15.6)$ & $66(9.5)$ & $2.71(1.01-7.25)$ & \\
\hline Current & $12(26.7)$ & $108(15.5)$ & $2.84(1.22-6.63)$ & \\
\hline Linear trend & & & & 0.007 \\
\hline \multicolumn{5}{|l|}{ Smoking status and duration } \\
\hline Never & $11(23.9)$ & $281(40.6)$ & 1 & 0.04 \\
\hline Former, 1-34 pack-years & $11(23.9)$ & $188(27.1)$ & $1.50(0.635-3.52)$ & \\
\hline Former, $>35$ pack-years & $12(26.1)$ & $117(16.9)$ & $2.62(1.12-6.11)$ & \\
\hline Current & $12(26.1)$ & $107(15.4)$ & $2.87(1.23-6.69)$ & \\
\hline Linear trend & & & & 0.005 \\
\hline ETOH (drinks/week) & $4.7(7.2)$ & $5.2(7.8)$ & - & 0.65 \\
\hline
\end{tabular}

ETOH, ethanol.

$P=0.006)$. Categorizing patients into groups with no smoking history, light smoking history $(<35$ packyears), and heavy smoking history ( $\geq 35$ pack-years), there was also an association with smoking history and the inlet patch $(P=0.02)$, along with evidence of a linear trend between increasing exposure to cigarettes and increased risk of having an inlet patch $(P=0.01)$ (Table 2). Analyzing tobacco use further, we found that there was a positive association between current cigarette use and the finding of an inlet patch $(P=0.04)$, again with a linear trend showing that current cigarette users had a higher likelihood of having an inlet patch than former smokers, who in turn had a higher likelihood than those who never smoked. The odds ratio (OR) of inlet patch for those who had quit recently $(2.71,95 \%$ confidence interval $[\mathrm{CI}]=1.01,7.25)$ approximated the OR of inlet patch for current smokers $(2.84,95 \% \mathrm{CI}=1.22$,
6.63), while those who quit more than a decade ago had an OR of $1.58(95 \% \mathrm{CI}=0.711,3.50)$, which was not significantly different than patients who never smoked (Table 2). Average typical alcohol intake per week was not associated with the inlet patch.

We considered that the education effect might be confounded by smoking on the prevalence of an inlet patch, or vice versa. Smoking (categorized as never, former, and current) was inversely correlated with education (categorized as high school or less, at least some college, or postgraduate degree) ( $P$-value < $0.001)$. Table 3 presents the ORs for these effects considered with and without mutually adjusting for each other. The estimate of the smoking effect was attenuated toward the null after adjusting for education; likewise, the estimate of the education effect was also attenuated toward the null after adjusting for smoking.

Table 3 Comparison of smoking and education status individually (crude) and in combination (adjusted)

\begin{tabular}{|c|c|c|c|c|}
\hline & \multicolumn{2}{|c|}{$n(\%)$} & \multirow{2}{*}{$\begin{array}{l}\text { Crude estimates } \\
\text { OR }(95 \% \text { CI })\end{array}$} & \multirow{2}{*}{$\begin{array}{l}\text { Adjusted estimates } \\
\text { OR }(95 \% \mathrm{CI})\end{array}$} \\
\hline & Inlet patch & No inlet patch & & \\
\hline \multicolumn{5}{|l|}{ Smoking status (alone) } \\
\hline Never & $11(23.9)$ & $281(40.6)$ & 1 & 1 \\
\hline Former & $23(50.0)$ & $305(44.0)$ & $1.93(0.922-4.02)$ & $1.69(0.788-3.62)$ \\
\hline Current & $12(26.1)$ & $107(15.4)$ & $2.87(1.23-6.69)$ & $2.02(0.809-5.06)$ \\
\hline$P$-value & & & 0.05 & 0.27 \\
\hline \multicolumn{5}{|l|}{ Education status (alone) } \\
\hline High school or less & $16(33.3)$ & $145(20.4)$ & 1 & 1 \\
\hline Some college up to bachelor's degree & $27(56.3)$ & $421(59.1)$ & $0.58(0.304-1.11)$ & $0.573(0.292-1.13)$ \\
\hline Advanced degree & $5(10.4)$ & $146(20.5)$ & $0.31(0.111-0.869)$ & $0.418(0.140-1.25)$ \\
\hline$P$-value & & & 0.06 & 0.17 \\
\hline
\end{tabular}




\section{DISCUSSION}

Most research has suggested that the inlet patch is a congenital malformation, but there have been associations noted in the past that may suggest it is an acquired condition, including a previously found association with Barrett's esophagus and with alcohol intake. ${ }^{9}$ That study failed to show an association between the inlet patch and smoking but only treated smoking as a dichotomous variable in the analysis. The Newly Diagnosed Barrett's Esophagus Study provides a unique opportunity to examine the prevalence and risk factors of gastric heterotopic mucosa in the upper esophagus in a population that more closely resembles the general population. The prior endoscopic studies on this topic have typically been a sampling ${ }^{3,4}$ of patients presenting for upper endoscopy for clinical indications, which likely introduces an element of selection bias into the estimate of the prevalence and associations. Additionally, this study included detailed surveys of patient's symptoms, medications, and habits, allowing us to determine if habits such as cigarette smoking are associated with the inlet patch.

Our study did find a relationship between cigarette use and the inlet patch. While the analysis here is performed in a case-control fashion and so is not sufficient to prove causation, there are several features of our analysis that do suggest a causal link. First, there was noted to be an increased risk as the number of pack-years of cigarette use increases. Second, former smokers had a lower prevalence of inlet patches than those who currently smoked. Third, those who had quit for more than 10 years had a prevalence of inlet patch that closely approximated that of the population who never smoked. However, the association of inlet patch with tobacco may have been confounded by education, which was also inversely associated with inlet patch.

A number or prior studies have reported the possible association between the presence of an inlet patch and symptoms of globus or dysphagia., ${ }^{4,12,13}$ There is also limited data to suggest ablation of inlet patch tissue with argon plasma coagulation reduces these symptoms. ${ }^{14}$ In our observational study, we did not find that patients with an inlet patch were any more likely to have these symptoms than patients without a patch. Results from prior studies may have been biased by selection effects for inclusion in the studies. Alternatively, perhaps only very large inlet patches are associated with symptoms. Our study did not find such an association, but we had limited statistical power to detect associations with large inlet patches as only 10 subjects were found to have a patch occupying more than $25 \%$ of the circumference of the esophageal lumen.

Our study has a number of limitations. We did not obtain histological confirmation of inlet patches, and the symptom questionnaires used were not validated. We limited our analysis of tobacco use to only cigarettes due to difficulty of quantifying equivalent exposure to cigar smoke and pipe smoke. Our survey did not query patients on smokeless tobacco products. Furthermore, we tested for multiple associations, so our finding might be solely due to chance. Finally, our study was limited to a male population, and $44 \%$ of the population were veterans, so these results may not be generalizable to other populations.

In summary, in a cross-sectional study of men undergoing upper endoscopy for research purposes, we found that inlet patches are common, not associated with symptoms, but positively associated with tobacco use and inversely associated with education. Further studies are warranted to understand whether inlet patches are acquired conditions and whether they cause esophageal symptoms in some individuals.

\section{References}

1 Schmidt F A. De mammalium oesophage atque ventriculo. Inaugural dissertation, Halle, Bethenea, 1805. Cited by von Rahden BHA, Stein HJ, Becker K et al. Heterotopic gastric mucosa of the esophagus: literature-review and proposal of a clinicopathologic classification. Am J Gastroenterol 2004; 99: 543-51.

2 Jabbari M, Goresky C A, Lough J, Yaffe C, Daly D, Cote C. The inlet patch: heterotopic gastric mucosa in the upper esophagus. Gastroenterology 1985; 89: 352-6.

3 Borhan-Manesh F, Farnum J B. Incidence of heterotopic gastric mucosa in the upper oesophagus. Gut 1991; 32: 968-72.

4 Maconi G, Pace F, Vago L, Carsana L, Bargiggia S, Bianchi Porro G. Prevalence and clinical features of heterotopic gastric mucosa in the upper oesophagus (inlet patch). Eur J Gastroenterol Hepatol 2000; 12: 745-9.

5 Jacobs E, Dehou M F. Heterotopic gastric mucosa in the upper esophagus: a prospective study of 33 cases and review of literature. Endoscopy 1997; 29: 710-5.

6 Yarborough C S, McLane R C. Stricture related to an inlet patch of the esophagus. Am J Gastroenterol 1993; 88: 275-6.

7 Sperling R M, Grendell J H. Adenocarcinoma arising in an inlet patch of the esophagus. Am J Gastroenterol 1995; 90: $150-2$.

8 Sanchez-Pernaute A, Hernando F, Diez-Valladares L et al. Heterotopic gastric mucosa in the upper esophagus ('inlet patch'): a rare cause of esophageal perforation. Am J Gastroenterol 1999; 94: 3047-50.

9 Avidan B, Sonnenberg A, Chejfec G, Schnell T G, Sontag S J. Is there a link between cervical inlet patch and Barrett's esophagus? Gastrointest Endosc 2001; 53: 717-21.

10 Rubenstein J H, Morgenstern H, Appelman H et al. Prediction of Barrett esophagus among men. Am J Gastroenterol 2013; 108: 353-62.

11 Rubenstein J H, Morgenstern H, Chey W D et al. Protective role of gluteofemoral obesity in erosive oesophagitis and Barrett's oesophagus. Gut 2014; 63: 230-35.

12 Alagozlu H, Simsek Z, Unal S, Cindoruk M, Dumlu S, Dursun A. Is there an association between Helicobacter pylori in the inlet patch and globus sensation? World J Gastroenterol 2010; 16: $42-7$.

13 Alaani A, Jassar P, Warfield A T, Gouldesbrough D R, Smith I. Heterotopic gastric mucosa in the cervical oesophagus (inlet patch) and globus pharyngeus-an under-recognised association. J Laryngol Otol 2007; 121: 885-8.

14 Bajbouj M, Becker V, Eckel F et al. Argon plasma coagulation of cervical heterotopic gastric mucosa as an alternative treatment for globus sensations. Gastroenterology 2009; 137: $440-4$. 